This is the final peer-reviewed accepted manuscript of:

M. Garai, F. Morandi, D. D'Orazio, S. De Cesaris, L. Loreti, Acoustic measurements in eleven Italian opera houses: Correlations between room criteria and considerations on the local evolution of a typology, Building and Environment, Volume 94, Part 2, 2015, Pages 900-912, ISSN 0360-1323

The final published version is available online at:

https://doi.org/10.1016/j.buildenv.2015.07.026

Rights / License:

The terms and conditions for the reuse of this version of the manuscript are specified in the publishing policy. For all terms of use and more information see the publisher's website.

This item was downloaded from IRIS Università di Bologna (https://cris.unibo.it/)

When citing, please refer to the published version. 


\title{
Acoustic measurements in eleven Italian opera houses: correlations between room criteria and considerations on the local evolution of a typology
}

\author{
M. Garai, F. Morandi, D. D’Orazio, S. De Cesaris, L. Loreti \\ DIN, University of Bologna, viale Risorgimento 2, 40136 Bologna, Italy
}

\begin{abstract}
Several studies focused on the acoustical characterisation of concert halls and opera houses analysing more or less homogeneous sets of halls and spotting reference criteria. This work presents the results of a detailed measurement campaign that was carried out over eleven small and mid-sized historical opera houses in the North of Italy with the aim of characterising this hall typology and to relate it to the reference literature. The cluster is intended to represent an adequate sample of case studies relative to different capacities and different design approaches that followed one another starting from the seventeenth century. The theatres were investigated using monaural and binaural techniques, performing impulse response measurements at each seat in the stalls and in each box. Seven ISO 3382 criteria are chosen to characterise these theatres and averaged over the three main listening areas denoted by the Italian opera house typology, i.e. the stalls, the boxes and the gallery. The correlation coefficients between interrelated criteria are presented and commented in relation to the architectural features of the theatres and to the existing literature.
\end{abstract}

Keywords: room acoustics, Italian opera houses, ISO 3382, monaural and binaural IRs

\section{Introduction}

Due to the complexity of the acoustic field in articulated closed spaces, architectural acoustics is often approached as a reverse-engineering problem: criteria, reference values and analysis methods are extrapolated comparing results from measurements in a set of case studies. In the literature different approaches have been proposed: prestige vs subjective ranking $[1,2]$, regional differentiation vs subjective tests (European halls [3], Finnish halls [4]), regional differentiation vs measured criteria (English halls [5], Danish halls [6], Spanish halls [7]), geometrical features vs measured criteria (concert halls [8], opera houses [9], chamber music halls [10]).

The Italian historical theatres don't have a common study comparable to the cited ones, apart from [11]. In fact, maybe due to the fragmentation of the Italian nation at the time of the theatres' design and construction, Italian type-related literature concerns sets of theatres belonging to specific geographic areas: Sicilian theatres [12], Apulian theatres [13], the collected works [14]; each author studies a "local" typology.

Email address: federica.morandi6@unibo.it (F. Morandi)
Taking into account the methods of the previous works on Italian historical theatres [15, 16, 17, 18, 19] and following the regional approach, the present study collects the results of a measurements campaign performed in the Italian theatres in Romagna, a region in the North of Italy. In particular, eleven historical opera houses were selected with capacities ranging from 224 to 835 seats, spanning a variety of cases. In each theatre, monaural and binaural measurements were performed in all seats with two analogous source positions and compared. Over 50,000 impulse responses (IR) were processed. The ISO 3382 [20] criteria are presented averaged over the audience, the boxes and the gallery and are commented in relation to the characteristic architectural features of the Italian historical theatres in order to highlight the acoustical peculiarity of this hall typology.

\section{The Italian historical opera houses}

\subsection{Notes about the Italian opera house typology}

The forerunners of the typology of the Italian historical opera house are two works by architect Aleotti: the “Teatro degli Intrepidi" in Ferrara (1605) [21], now demolished, and the Farnese Theatre in Parma (1610) [22]. In these two theatres, Aleotti introduced the presence of 
an arch between the auditorium and the stage, called proscenium arch, which materialised the difference between the reality and the theatrical fiction. This feature became a primary acoustic element of the Italian theatre; in fact it splits the volume of the stage house (necessary for the handling of the scenes) from the volume of the audience.

The development of the typology was made possible by the combined efforts of theoretical treaties and the transmission of the constructive technologies between generations of builders. Since theatres were mainly built of wood, few of them survived fires. Thus it is difficult to derive the development of this typology basing on the few intact examples. On the other hand, many theoretical treaties have survived the last five centuries, allowing to depict an evolutionary trace of that typology.

From the point of view of a contemporary acoustician, the old treaties point out all the critical aspects of the design of an opera house. Aleotti (1605) highlighted the relevance of the proscenium arch. Carini-Motta [23] (1676) emphasised the separation of the acoustic volumes of the stage and the audience, underlining the relation between the theatre with boxes and the strict class division of the time. Milizia [24] (1773), inspired both by French revolutionary ideas and by some acoustical concepts, criticised the boxes as they cut and reverberate the resonant air, confusing the perceived sound. Riccati [25] (1790) discussed the homogeneity of direct sound to the listeners, proposing some concave shapes for the stalls area and identifying the bell-shape as the best performing. Rizzetti [26] (1792) also studied the diffusion of the sound, proposing the elliptical shape as the optimum. Niccolini [27] (1816) analysed the energetic transmission between stage and main hall and the relationship between reverberation and acoustic mean free path. He identified in the stage opening and the vault two very important features of the theatre. Beccega [28] (1817) analysed the optimal geometric proportions concerning all the parts of the theatre and the echo-flutter phenomena. The optics-acoustics dualism has often been useful to these authors, being the knowledge in optics at that times most advanced than the one in acoustics. So, during the $18^{\text {th }}$ and $19^{\text {th }}$ centuries, the mixtilinear shape of the Italian theatre was developed from many architects, which were experimenting new solutions in order to improve the acoustical conditions and the possibility to have optimised visuals.

\subsection{The 11 investigated Italian historical opera houses}

The theatres investigated in this study represent an adequate sample of case studies relative to the different design approaches presented above. The theatres are:

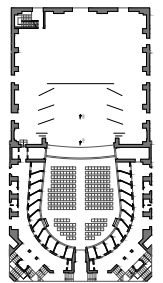

(a) BON

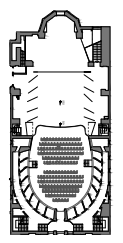

(e) STI

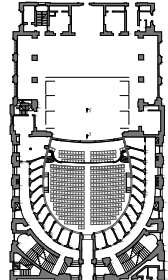

(b) ALI

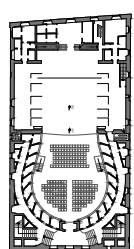

(c) MAS

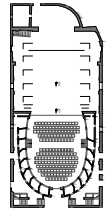

(d) $\mathrm{ROS}$

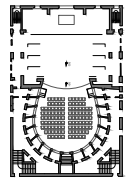

(f) GOL

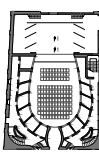

(g) DRA

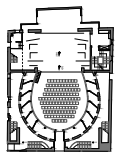

(h) RUS

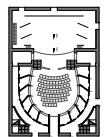

(i) $\mathrm{CES}$

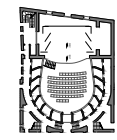

(j) $\mathrm{CER}$

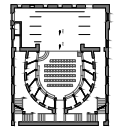

(k) PET
Figure 1: Plans of the eleven investigated theatres with the source positions on the stage (metric scale).

the Bonci Theatre in Cesena (BON), the Alighieri Theatre in Ravenna (ALI), the Masini Theatre in Faenza (MAS), the Rossini Theatre in Lugo (ROS), the Stignani Theatre in Imola (STI), the Goldoni Theatre in Bagnacavallo (GOL), the Dragoni Theatre in Meldola (DRA), the Communal Theatres in Russi (RUS), Cesenatico (CES), Cervia (CER) and the Petrella Theatre in Longiano (PET). The plans of these theatres are reported in Fig. 1 using the same scaling factor (metric scale).

The peculiarity of these theatres is that they belong to the same geographical and historical context; they were all built within a time range of 130 years and they all lie within a radius of $30 \mathrm{~km}$. As a consequence, the designers and the workforce involved in the construction of the theatres were often the same. These theatres shared the political events related to the foundation of the Reign of Italy (1861) and World War II, during which most of them were severely damaged, sacked and used as warehouses, public toilets, cellars or field hospitals. In the twenties, some of these theatres were equipped with an orchestra pit, whose construction changed the role of the proscenium arch. In particular, in many cases the stage was backed (BON, ALI, STI, CES) and as a conse- 

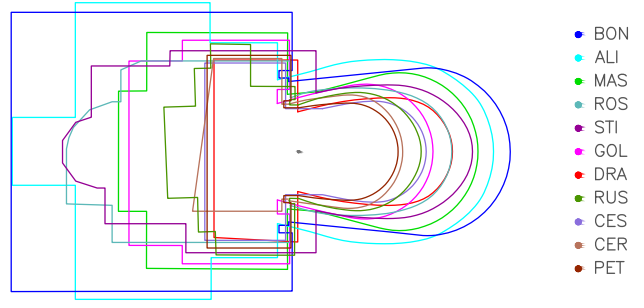

Figure 2: Superposition of the internal shape of the main hall and the stage of the eleven investigated halls. The plans are aligned with respect to the edge of the stage.

quence the proscenium arch could not provide anymore the typical strong early reflection on the audience.

A synthesis of the architectural features of these theatres can be found in Table 1 . The capacity of these theatres varies from 835 (ALI) to 224 (CER) seats. Within this range, it is possible to distinguish between big-sized theatres (ALI, BON), medium-sized theatres (MAS, ROS, STI, GOL) and small theatres (DRA, RUS, CES, CER, PET). Actually this distinction can be operated only for this set of theatres, as bigger Italian historical opera houses (e.g. the Teatro Massimo in Palermo, with a total capacity of 1,358 seats) should be more properly regarded as "big". The current capacities of the theatres are totally different from the original numbers: a symbolic example is the Communal Theatre in Cervia, which at the time of its construction had a capacity of 600-700 people, now reduced to 224 people.

Since the internal proportions of the theatres are quite standard, it is possible to notice from Tab. 1 that the ratio between the volume of the audience and the total capacity of the theatres is almost constant in the theatres under study. The shape of the main hall varies significantly between the theatres, following the criteria of the design school of thought among those pointed out previously. In fact, though they can all be abscribed to the same typology, the shape varies from elliptical to horseshoe, as displayed in Fig. 2.

\section{Measurement setup}

The eleven theatres were investigated using monaural and binaural techniques in an unoccupied state according to ISO 3382 [20]. The measurements were carried out between May 2014 and March 2015.

The source positions on the stage were chosen similarly in all the theatres and are displayed in Fig. 3. SS1 lies in the front of the stage, at $1 \mathrm{~m}$ from the edge; SS2

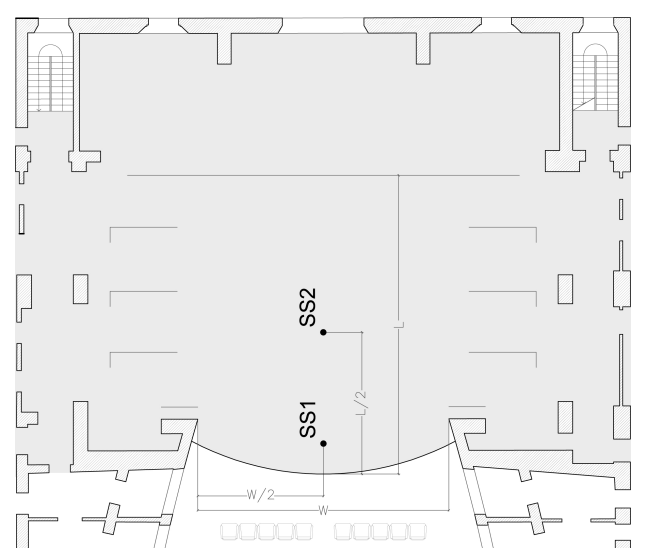

Figure 3: Position of the sound sources on the stage relative to the position of the back wings and the proscenium arch. $W$ is the width of the proscenium arch, $L$ is the depth of the back wing measured from the edge of the stage. SS1 is the source on the proscenium while SS2 is the source in the centre of the area enclosed by the wings.

in a barycentric position on the stage, i.e. at the middle point between the edge of the stage and the back lining. The sound sources were a subwoofer and a dodecahedron. The subwoofer was placed directly on the stage and the mechanical coupling with the stage was prevented by means of a neoprene layer; the dodecahedron stood over the subwoofer, at a height of $1.2 \mathrm{~m}$ approximately. The IRs measured with the subwoofer were used for the analysis in the $63 \mathrm{~Hz}$ and $125 \mathrm{~Hz}$ octave bands while the analysis in the $250-4,000 \mathrm{~Hz}$ octave bands was conducted over the IRs measured using the dodecahedron as source.

The measurement campaign was characterised by a huge amount of measurements. In the stalls, monaural IRs measurements were performed at all seats for the two source positions. Binaural measurements were performed on a selection of points ranging from 1 every 2 seats to 1 every 4 seats. In each box, monaural and binaural measurements were performed placing the microphone in the front position. In the gallery, measurements were taken in correspondence to the seats in the boxes, with some slight differences depending on the setting of the gallery. Over 50,000 IRs were processed. The height of the microphone was kept at $1.2 \mathrm{~m}$.

This paper reports only measurements performed with the orchestra pits closed, in order to allow a horizontal comparison between the theatres, as some of them do not have it.

In each theatre, the amount and type of curtains were annotated. The curtains were set for a standard performance of a medium-sized orchestra in the large theatres and in the standard configuration for the smaller the- 
Table 1: Architectural features of the eleven investigated Italian historical opera houses.

\begin{tabular}{|c|c|c|c|c|c|c|c|c|c|}
\hline Hall & & $\begin{array}{l}V_{t o t} \\
\left(m^{3}\right)\end{array}$ & $\begin{array}{l}V_{\text {hall }} \\
\left(\mathrm{m}^{3}\right)\end{array}$ & $\begin{array}{l}N \\
-\end{array}$ & $\begin{array}{c}N_{\text {stalls }} \\
-\end{array}$ & $\begin{array}{c}V_{\text {hall }} / N \\
\left(\mathrm{~m}^{3} / \text { seat }\right)\end{array}$ & $\begin{array}{c}\text { Tiers } \\
-\end{array}$ & $\begin{array}{c}\text { Inauguration } \\
\text { year }\end{array}$ & $\begin{array}{l}\text { Pit } \\
(y / n)\end{array}$ \\
\hline BON & Cesena, Teatro Bonci & 16,490 & 3,130 & 798 & 222 & 3.9 & 4 & 1846 & $\mathrm{y}$ \\
\hline ALI & Ravenna, Teatro Alighieri & 12,960 & 3,360 & 835 & 370 & 4.0 & 4 & 1852 & $\mathrm{y}$ \\
\hline MAS & Faenza, Teatro Masini & 7,540 & 2,580 & 500 & 190 & 5.2 & 4 & 1788 & $\mathrm{y}$ \\
\hline ROS & Lugo, Teatro Rossini & 5,790 & 1,490 & 448 & 161 & 3.3 & 4 & 1761 & $\mathrm{n}$ \\
\hline STI & Imola, Teatro Stignani & 6,260 & 1,750 & 550 & 162 & 3.2 & 3 & 1812 & $\mathrm{y}$ \\
\hline GOL & Bagnacavallo, Teatro Goldoni & 6,250 & 1,430 & 390 & 112 & 3.7 & 3 & 1845 & $\mathrm{y}$ \\
\hline DRA & Meldola, Teatro Dragoni & 2,880 & 1,140 & 318 & 124 & 3.6 & 3 & 1838 & $\mathrm{n}$ \\
\hline RUS & Russi, Teatro Comunale & 2,910 & 900 & 305 & 110 & 2.9 & 2 & 1887 & $\mathrm{y}$ \\
\hline CES & Cesenatico, Teatro Comunale & 2,760 & 870 & 271 & 69 & 3.2 & 2 & 1865 & $\mathrm{y}$ \\
\hline CER & Cervia, Teatro Comunale & 2,270 & 730 & 224 & 76 & 3.3 & 2 & 1862 & $\mathrm{n}$ \\
\hline PET & Longiano, Teatro Petrella & 2,620 & 630 & 241 & 62 & 2.6 & 2 & 1870 & $\mathrm{n}$ \\
\hline
\end{tabular}

atres. For the latter ones, the minimum amount of absorptive material on the stage suggested in the Charter of Ferrara [15] of $500 \mathrm{~m}^{2}$ could not be satisfied.

\section{Analysis of the results}

The results of the measurement sessions are here presented by means of seven criteria extracted according to ISO 3382-1 [20]: $T_{30}, E D T, C_{80}, T_{s}, G, I A C C_{E}$, $I A C C_{L}$.

$T_{30}, E D T, C_{80}, T_{s}$ are extracted using the Matlab ITA-toolbox [29], while $G$ and IACC are extracted using internally developed codes compliant with ISO 3382-1 [20]. The extraction of $G$ follows the proposal of Hak et al. [30] rather than the ISO prescriptions: the denominator is built by an energetic average of six IRs measured at $1 \mathrm{~m}$ from the source (to overcome problems arising from the directivity of the cones), windowed over $10 \mathrm{~ms}$ and brought back to a distance of $10 \mathrm{~m}$ by means of a logarithmic difference.

The results are reported in Tables 3, 4 and 5 averaged over the measurement position in stalls, the boxes and the galleries respectively and averaged over the octave bands centred at 500, 1,000 and 2,000 Hz. The choice of presenting the values of the criteria averaged over each area of the theatre (stalls, boxes, gallery), is meant to provide an overall description of the acoustics of these theatres in line with the previous literature $[8,7,9,10,33]$.

The analysis of the ISO 3382 [20] criteria identifies the theatres under study as optimal for listening to opera and opera reductions, the genres for which they were built, but not so for symphonic music[34]. These theatres are characterised by very proportionate spaces, which provide strong early reflections related to a high degree of intimacy [9]. The listener is never placed too far from the source; this, united with the concave shape of the audience, provides reasonably high $G$ values all over the hall.

$I A C C_{e}$ values are generally low due to the early reflection pattern characteristic of these theatres. $I A C C_{l}$ is almost constant in all theatres, indicating that the earlylate threshold of $80 \mathrm{~ms}$ might need to be adapted to the statistical properties of the impulse responses [35].

Tables 3, 4 and 5 also report the value of the $B R$. The values are always greater than one; in the stalls they range between 1.22 (RUS, SS2) to 1.74 (CER, SS2). In the literature, the $B R$ calculated in occupied halls has lower values, e.g. ranging from 1.07 to 1.32 in [9]. Since the occupied state is likely to influence mostly the high frequency, i.e. decreasing the denominator, the investigated theatres show to be sensitively "warmer" than other opera houses analysed in the literature.

Considering valid the experimental correlations between ISO criteria and subjective preference, these theatres locate themselves in a good position in the global assessment ranking of concert hall as reported in the most recent studies, as [36]. In this work, some adjectives are spot that are important for the perceptive evaluation both for expert and non-expert listeners. In particular the adjectives good direct sound, clear, bright, warm, close are well-ranked in both categories and can be easily correlated with the ISO values presented above. The issue that is currently being discussed is the validity of the classical relationship between objective parameter and subjective assessment [37], topic which has partially being addressed by the authors [38] through questionnaires submitted to expert musicians who play in these theatres.

Given the great availability of measurements, some statistical values calculated over the stalls area is pre- 
sented in Tables 6 and 7. Mean value, standard deviation and skewness are evaluated over a selection of criteria $\left(E D T, T_{30}, C_{80}, T_{s}\right.$ e $G$ ) in the octave bands centred at 500, 1,000 and 2,000 Hz. Reverberation times show low standard deviation, denoting a certain homogeneity in space. The criteria which strongly depend on the early reflections have a strong dependance on the spatial position of the measurement point and a greater variability. This translates into an increase of standard deviation and to values of skewness which might be correlated to the focussing effects typical of these theatres.

In the following, some correlations between interrelated criteria are discussed in the light of the results presented above.

\section{1. $T_{30}$ vs Volume}

The statistical reverberation theory formulates the relationship between the reverberation time and the volume of the enclosed space [31]. Thus the first correlation is searched between the volumes of the main halls of the investigated theatres and the measured $T_{30}$. In coherence with $[9,32]$, the volume taken into account is the one of the main hall, excluding the volumes of the flytower, the boxes and the gallery.

Fig. 4 shows the correlation for the stalls of the eleven theatres. It shows that there is a general increase in reverberation time corresponding to an increase in volume, consistently with the reverberation theory. The stalls area is characterised by a very absorbing surface (seats), a very reflecting surface at the listeners' height (plaster made of marble powder and slaked lime, called marmorino) and by the presence of boxes.

On the right side of Fig. 4 it is possible to identify the two biggest theatres, BON and ALI. The volumes of the main halls of these two theatres are comparable (see Tab. 1), but the reverberation times change quite significantly. This is due to the fact that in ALI the number of seats in the audience is 370 , versus the 222 seats in BON. Moreover, while in BON the seats are poorly absorbing (wood seats with velvet upholstering), in ALI the seats are heavily upholstered $[4,31]$. This causes a reduction of reverberation time of about $27 \%$. BON is also characterised by a huge stage house: in fact, while for all the other theatres the reverberation time does not change significantly with the source in position $\mathrm{SS} 2$, in this case it displays a remarkable increase. GOL is also highlighted in Fig. 4 as its behaviour does not follow the general trend.

\section{2. $E D T / V$ vs $G$}

It has been proved that if Sabine's theory is valid, then $G$ is proportional to $T_{30}$ and inversely proportional

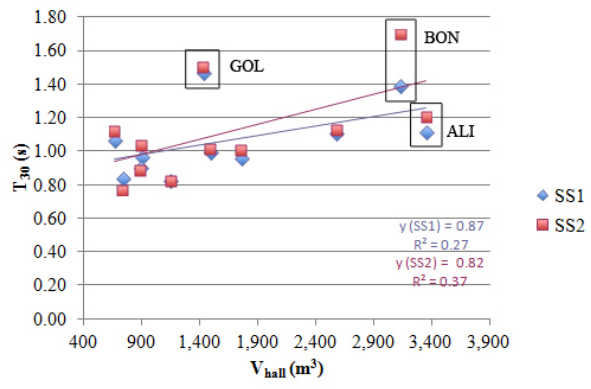

Figure 4: Reverberation time $T_{30,3}$ (s) averaged in the stalls of each theatre plotted against the volume $V\left(\mathrm{~m}^{3}\right)$ of the main hall of the respective theatre.

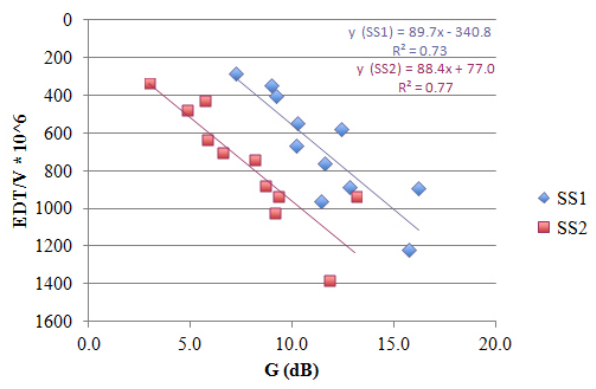

Figure 5: Early decay time $E D T_{3}$ (s) divided by the volume $V\left(\mathrm{~m}^{3}\right)$ of the hall plotted against the strength $G_{3}(\mathrm{~dB})$. The $E D T_{3}$ and $G_{3}$ are the average over the measurements performed in the stalls of each of the eleven historical opera houses investigated.

to $V[9,10]$. Thus, Fig. 5 plots the $E D T / V$ ratio vs the $G$ values. Hidaka found a high correlation between $E D T / V$ and $G$ for the theatres with highly absorbent stage houses (line B in [9]). The role of the curtains is confirmed by the set of data provided in this work. With both source positions SS1 (proscenium) and SS2 (centre stage), the linear regressions calculated over the eleven halls have the same angular coefficients, with a trend that recalls closely the one found in [9]. The linear regression calculated for the source position SS2 displays a higher correlation coefficient than the one found for SS1 ( $r=0.88$ and $r=0.85$ respectively), highlighting:

1. the influence of the stage absorption on the first part of the energy decay curve measured in the stalls area;

2. the greater relative weight of the energy of the direct field to the reverberant field when the source is placed in the proscenium, i.e. between the coupled volumes of the stage house and the main hall. 


\section{3. $E D T$ vs $T_{30}$}

The $E D T / T_{30}$ ratio can be considered as a measure of the directness of the design of a hall and generally takes values between 0.8 and 1.1 [33].

In the Italian historical opera houses, the typical IRs are characterised by the presence of strong early reflections provided by the proscenium, the vault and, for the stalls area, from the smooth side walls. Thus according to Barron [39] the decays of this typology can be identified as "cliff-type" decays. In this case the EDT is smaller than the $T_{30}$; it comes to the eye quite directly observing the positive slope of the trend displayed in Fig. 6. Irrespective of the source position, the $E D T / T_{30}$ ratio takes values of $0.8,0.6$ and 0.8 for the stalls, the boxes and the gallery respectively.

Looking more in detail at Fig. 6 a, it is possible to notice that the linear regressions calculated with SS1 and SS2 display the same angular coefficient, denoting the same kind of decay. With the source in position SS2, the intercept value is greater, indicating the different contribution given by the early reflections from the proscenium and the stage.

In the boxes (Fig. 6 b), the $E D T / T_{30}$ ratio is not dependent on the source position and poorly dependent on the theatre considered. While in the stalls the direct sound comes with strong early reflections (proscenium, vault, side walls) and is followed by the reverberant field, the field inside the boxes is strongly related to the field which originates inside the box; this results in a decrease in the $E D T / T_{30}$ ratio.

\section{4. $E D T$ vs $C_{80}$}

$C_{80}$ usually displays a strong negative correlation with EDT [33]. This is confirmed also for this set of measurements both in the stalls, in the boxes and in the gallery.

In all the theatres under study, the mean values of $E D T$ in all the regions of the hall range from 0.64 (CER, boxes SS2) to 1.70 (GOL, gallery SS2). That locates the $80 \mathrm{~ms}$ threshold inside the decay range used for the derivation of EDT. It should be noted that, while the theatres analysed in [9] show EDT values around $2 \mathrm{~s}$, in the theatres analysed in the present work the EDT values are halved. This implies that, in the theatres under study, the numerator of the clarity refers roughly to the first $4 \mathrm{~dB}$ of the energy decay, while in [9] it approximately refers to the first $2 \mathrm{~dB}$ of decay. This could endorse the high correlation value found between $E D T$ and $C_{80}$.

The same shift that was noticed for the $E D T / T_{30}$ ratio in the stalls with source in SS1 is displayed here:

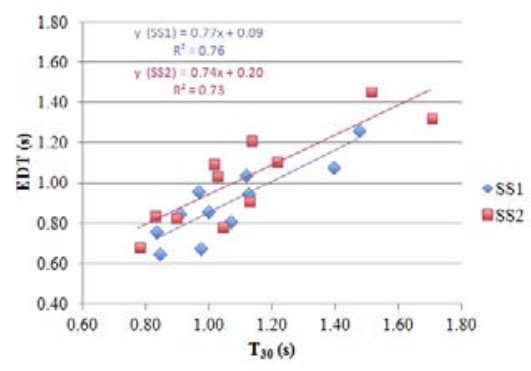

(a) Stalls

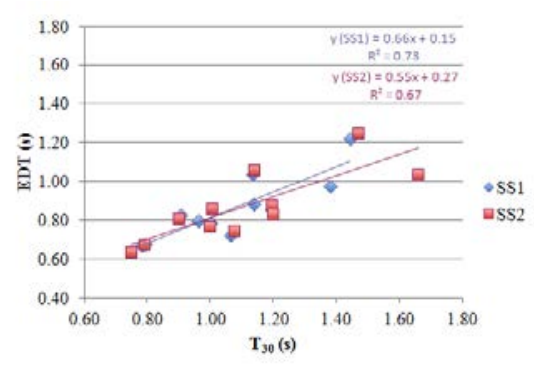

(b) Boxes

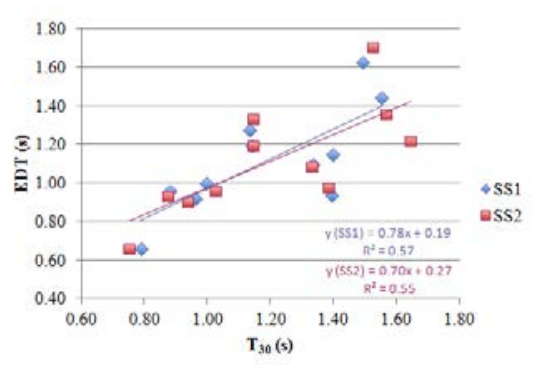

(c) Gallery

Figure 6: Early decay time EDT (s) plotted against the reverberation time $T_{30}$ (s) averaged in the stalls (a), in the boxes (b) and in the gallery (c) of the eleven investigated historical opera houses.

in fact, with the back source position, the reverberation time inside the hall increases as the stage house plays a key role. Thus, having the same EDT, an increase in $T_{30}$ translates into a decrease in $C_{80}$ due to an increase in the integral at the denominator.

\subsection{Coupling effect between the flytower and the audi- ence}

The ratio of standard ISO 3382 criteria provides a tool to identificate the coupling effect due to the presence of multiple volumes. This is particularly critical for historical opera house as this typology is strictly split between the volume of the stage and the volume of the audience, the proscenium arch being the filter between 


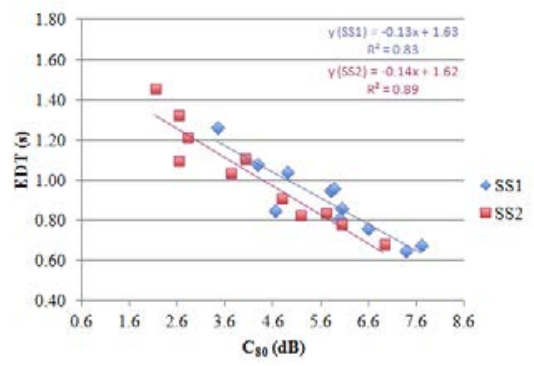

(a) Stalls

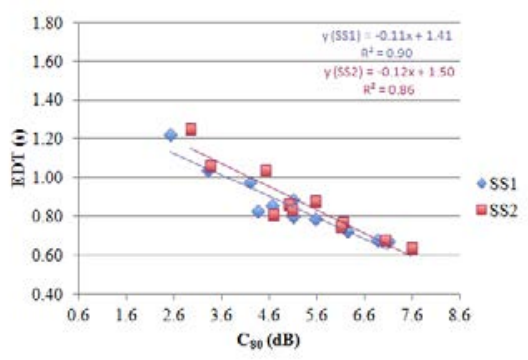

(b) Boxes

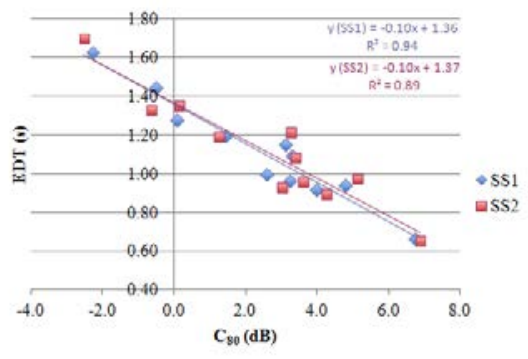

(c) Gallery

Figure 7: Early decay time $E D T_{3}$ (s) plotted against the clarity $C_{80,3}$ $(\mathrm{dB})$ averaged in the stalls (a), in the boxes (b) and in the gallery (c) of the eleven investigated historical opera houses.

the two. The coupling effect between volumes emerges from the variation in slope of the energy decay curve. The first ratios proposed to quantify the coupling effects were the $T_{30} / T_{15}$ and $T_{60} / T_{15}$ [40]. Xiang and Goggans $[41,42]$ developed a technique to extract multirate decays from multislope IRs based on the Bayesian analysis. This technique allows to identify dynamically decay rates, decay ranges and turning points on each IR, providing a huge amount of information related to the nature of the energy decay curve. On one hand, this is useful when analysing single IRs; on the other hand, when dealing with a global behaviour of a performance space, it does not allow to evaluate the average behaviour between all IRs as all the decay ranges and turning points

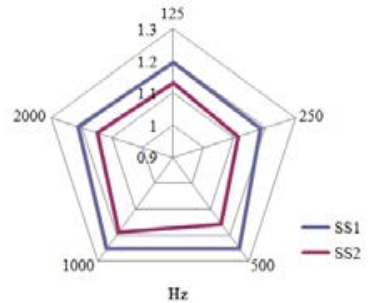

(a) $L D T / T_{10}$ ratio

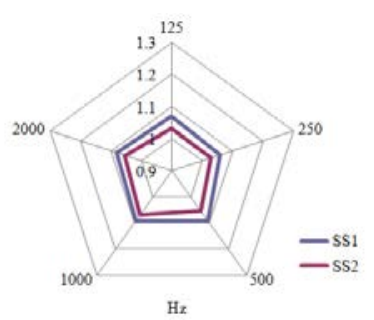

(b) $T_{30} / T_{15}$ ratio

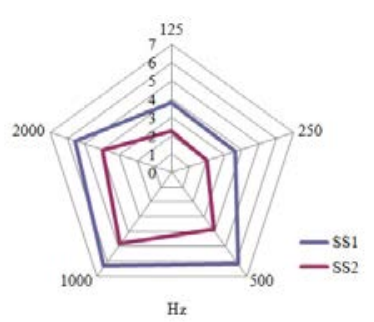

(c) Degree of curvature $C$

Figure 8: Coupling factors.

are different. Bradley and Wang [40, 43] compared several methods to evaluate the multislope decay in IRs: according to the final results, the metrics that described effectively the coupling effect are $T_{30} / T_{15}$ and $L D T / T_{10}$ . While $T_{30}, T_{15}$ and $T_{10}$ are commonly found in the literature, $L D T$ is the late decay time, defined as the reverberation time extracted from the range -25 to $-35 \mathrm{~dB}$. It has the advantage of conducting the evaluation over a $10 \mathrm{~dB}$ range as for $T_{10}$ and to consider non-overlapping regions of the IR. As Barron [39] pointed out, the different part of the decay curve depend on each other and thus choosing close or overlapping regions might be misleading. Since the aim of this work is an horizontal comparison between the acoustics of several theatres, and thus a global characterisation is needed for a whole hall, the metrics proposed by Bradley and Wang [43] are chosen to detect the coupling effect. Moreover, there is another criterion proposed by the ISO 3382-2 [44] aimed at pointing out the non-linearity of the decay, i.e. the degree of curvature $\mathrm{C}$. 
Figure 8 shows two coupling coefficients, $L D T / T_{10}$ and $T_{30} / T_{15}$, together with the degree of curvature $C$. Each criterion is averaged in the stalls area of each theatre in the respective octave band (125 to 2,000 Hz). Then the ratios are computed and finally averaged over the eleven theatres. The choice of the two source positions is useful to determine whether a coupling effect occurs between the two volumes. The source position SS2 lies in the centre of the stage, i.e. totally belongs to one of the volumes, while the position SS1 is on the proscenium, i.e. in the middle between the coupled volumes. Two observations should be done. First, the $L D T / T_{10}$ ratio returns greater values than the $T_{30} / T_{15}$ ratio. The lower sensitivity of the last ratio could be due to the issues raised above regarding the overlapping regions, which in this case occurs for $15 \mathrm{~dB}$. Second, the ratios are influenced differently from the source position. When the source is placed in the centre of the stage (SS2), i.e. in one of the two volumes, the $L D T / T_{10}$ ratio assumes values in the range 1.1-1.2. Shifting the source towards the proscenium (SS1), this ratio is increased of about 0.1 ; the coupling effect becomes quite significant due to the delay of the energy radiated towards the flytower. The $T_{30} / T_{15}$ ratio seems not to depend significantly upon the source shift. The variability of the linearity of the decay with the source position is also confirmed by the average degree of curvature [44]. Figure $8 \mathrm{c}$ shows that, while the decay is almost linear for SS2 (lower than 5\%), for source position SS1 this value grows significantly, especially at mid-high frequencies.

\section{Discussion}

In order to provide a comparison with the literature, correlation coefficients are calculated among interrelated criteria and commented in relation to those provided in other works $[9,10,45]$. A linear regression was fit to the plots $T_{30,3}$ vs $V, E D T_{3}$ vs $T_{30,3}, E D T_{3}$ vs $C_{80,3}$ and $T_{30,3}$ vs $C_{80,3}$ and the Pearson's $r$ are reported in Tab. 2.

1. The $T_{30} / V$ correlation coefficients are only reported for the stalls area as related to the volume and then to the reverberation theory.

2. The $E D T / T_{30}$ correlation coefficients are lower than the ones found in $[9,10]$ but in line with the values found in [45]. This might be due to the characteristic "cliff-type" shape of the IRs measured inside Italian opera houses, which adds a huge variability on the early decay among different theatres. The discrepancies might be explained considering that in $[45,9]$ only few of the analysed theatres show this feature.

3. The $E D T / C_{80}$ correlation coefficients are significantly high in all regions of the theatres, displaying values higher than the ones reported in the literature. This is particularly marked in the gallery and might be explained considering the poor contribute of the direct field with respect to the first part of the energy decay curves.

4. On the contrary, the $T_{30} / C_{80}$ correlation coefficients are quite low compared to the literature ones, showing that the $C_{80}$ is barely influenced by the energy decay curve below $-5 \mathrm{~dB}$.

5. The coupling coefficients $L D T / T_{30}, T_{30} / T_{15}$ and the degree of curvature showed that there is consistent detection of the coupling effect, which becomes marked when the source position is on the proscenium.

In addition to this, it is interesting to notice that, when analysing criteria related to the deterministic part of the signal $\left(E D T, C_{80}\right)$ in the boxes, a distinction should be made between the small and the mid-sized theatres. Small theatres have two tiers of boxes while mid-sized theatres have four tiers of boxes. Since the values are presented averaged over all the boxes, the analysis of the results should take into account that the acoustics inside the boxes might change significantly in the two cases, as in the latter case (four tiers of boxes), the mean value considers also measurement positions blind to the source. For instance, with respect to the $E D T$ and $T_{30}$ values measured in the stalls, mid-sized theatres show smaller $E D T$ and unchanged $T_{30}$, while small theatres have slightly greater $T_{30}$ and unchanged $E D T$ values (see Tabs. 3 and 4). This might explain the difference in slope of the $E D T / T_{30}$ ratio in the boxes.

The spatial distribution of the criteria inside the hall is also of interest. Figure 9 reports interpolation maps for the criteria $E D T$ and $T_{30}$ at $1,000 \mathrm{~Hz}$ in the Bonci and Rossini theatres. These two theatres are chosen to emphasise the difference of the shape (for how small it is) on the spatial distribution of two closely related criteria. The Bonci Theatre has a typical horse-shoe shape while the Rossini Theatre has an elliptical plan. As clearly shown by the maps, reverberation time is uniform in the stalls area. The early decay time on the contrary has a spatial distribution which is strongly dependent on the position of both the source and the receiver, being determined by the early reflections regime. The skewness in this case assumes values which might be related to the spatial distribution of the criteria. In fact, the variation of the $E D T$ in these halls is due to the presence of strong 
Table 2: Comparison between the correlation coefficients among objective acoustical criteria derived from the literature[9, 10, 45] and calculated from the measurements in eleven Italian historical opera houses. (a) See text for explanation.

\begin{tabular}{|c|c|c|c|c|c|c|c|c|c|}
\hline & H. et al[9] & H. et al[10] & C. et al[45] & $\begin{array}{l}\text { Stalls } \\
\text { SS1 }\end{array}$ & $\begin{array}{c}\text { Stalls } \\
\text { SS2 }\end{array}$ & $\begin{array}{c}\text { Boxes } \\
\text { SS1 }\end{array}$ & $\begin{array}{c}\text { Boxes } \\
\text { SS2 }\end{array}$ & $\begin{array}{c}\text { Gallery } \\
\text { SS1 }\end{array}$ & $\begin{array}{c}\text { Gallery } \\
\text { SS2 }\end{array}$ \\
\hline$T_{30,3}$ vs $\mathrm{V}$ & 0.63 occ & $<0.6$ & (a) & 0.52 & 0.61 & (a) & (a) & (a) & (a) \\
\hline$E D T_{3}$ vs $T_{30,3}$ & 0.98 & 0.98 & 0.82 & 0.87 & 0.86 & 0.86 & 0.82 & 0.75 & 0.74 \\
\hline$E D T_{3}$ vs $C_{80,3}$ & -0.86 & -0.96 & -0.69 & -0.91 & -0.95 & -0.95 & -0.93 & -0.97 & -0.94 \\
\hline$T_{30,3}$ vs $C_{80,3}$ & -0.88 & -0.98 & -0.69 & -0.76 & -0.73 & -0.79 & -0.69 & -0.59 & -0.50 \\
\hline
\end{tabular}

early reflections; it can be visualised easily considering the spatial distribution of the EDT in the Bonci Theatre with source in SS2; the rear of the hall show low values of EDT compared to the front which cause the high standard deviation and the asymmetry of distribution of values. In the Rossini Theatre, the skewness assumes a positive value with the source in SS1 and a negative value when the source is in SS2, reflecting closely the spatial distribution of the EDT in the hall. The maps also show that the acoustics of these halls is characterised by relatively homogeneous listening areas, for instance considering the front and rear part of the hall in Figure $9 \mathrm{f}$ and $9 \mathrm{~h}$. The distribution of these criteria inside opera houses has been preliminary discussed by the authors [46] and is being currently submitted to a deeper investigation.

\section{Conclusions}

A detailed measurement campaign was carried out in eleven small and mid-sized Italian historical opera houses built in the same area in the North of Italy (Romagna). Seven ISO 3382 monaural and binaural criteria were chosen in order to attempt a characterisation of the Italian opera houses and to compare their acoustics to the existing literature. In particular, $T_{30}, E D T, C_{80}, T_{s}$, $G, I A C C_{e}, I A C C_{l}$ were extracted from the impulse responses measured at all seats of the eleven theatres with two source positions.

The results of the measurements, in line with the existing literature, define a typology of halls characterised by low reverberation time, low EDT and high values of $C_{80}$, i.e. optimal for listening to Italian operas and opera reductions. The strength factor $G$ is quite high, both due to the dimensions of the examined theatres and to the concave shape of the main halls. The high $B R$ values indicate a warm sound perception, and the $I A C C_{e}$ values are also quite low, due to the early reflection pattern characteristic of these theatres. This feature corresponds to a small $A S W$ and thus to an easy localisation of the sound source on the stage (singer). The availabil-

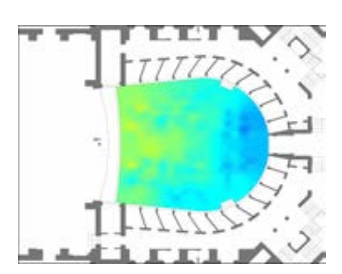

(a) EDT SS1 $\mu=1.06$, $\sigma=0.17, s=-0.19$

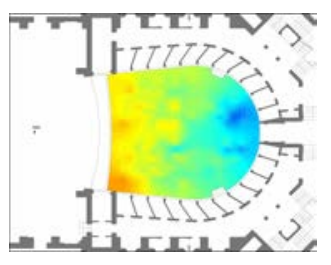

(c) $E D T \mathrm{SS} 2 \mu=1.30$, $\sigma=0.25, s=-0.88$

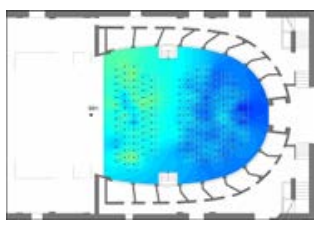

(e) $E D T$ SS1 $\mu=0.83$, $\sigma=0.19, s=0.20$

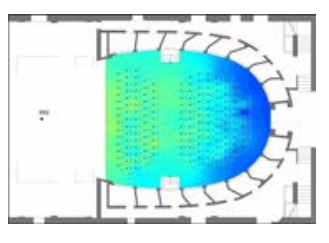

(g) $E D T$ SS2 $\mu=1.00$, $\sigma=0.17, s=-0.92$

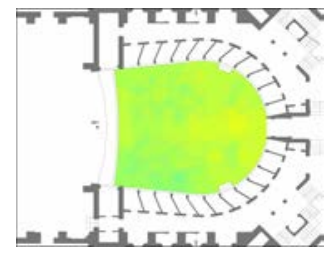

(b) $T_{30} \mathrm{SS} 1 \mu=1.36, \sigma=$ $0.05, s=0.04$

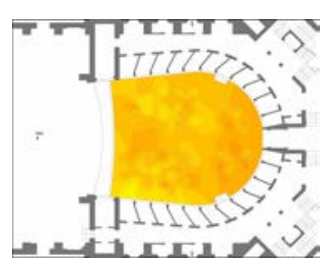

(d) $T_{30} \mathrm{SS} 2 \mu=1.69, \sigma=$ $0.05, s=0.01$

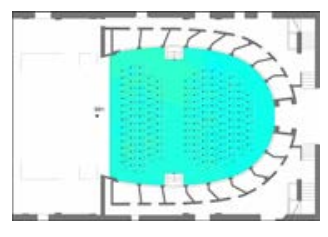

(f) $T_{30} \mathrm{SS} 1 \mu=0.99, \sigma=$ $0.03, s=-0.003$

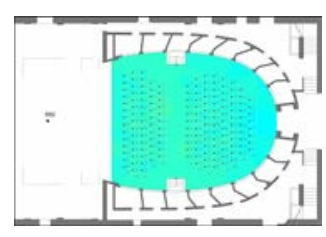

(h) $T_{30} \mathrm{SS} 2 \mu=1.01, \sigma=$ $0.03, s=-0.34$

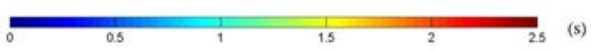

Figure 9: Interpolation maps of $E D T$ and $T_{30}$ in the Bonci Theatre (a-d) and Rossini Theatre (f-i) at 1,000 Hz. 
ity of these data also allowed a preliminary analysis on the statistical distribution of the criteria related to the geometry of the halls.

Correlation coefficients were calculated among interrelated criteria: $T_{30}$ vs $V, E D T / V$ vs $G, E D T$ vs $T_{30}$, $E D T$ vs $C_{80}$ and $T_{30}$ vs $C_{80}$. It was found that:

1. The correlation between $E D T / V$ and $G$ for the two source positions points out the influence of the stage absorption on the first part of the energy decay in the stalls, which will require further investigation.

2. The ratio between $E D T$ and $T_{30}$, smaller than one in the investigated halls, identifies the decay inside the Italian historical opera houses as a "cliff-type" decay, characterised by the early reflection pattern typical of these halls.

3. A strong correlation is also found between the $E D T$ and the $C_{80}$, for which the correlation coefficients are higher than those provided in the literature. On the opposite, the reverberation time $T_{30}$ and the clarity $C_{80}$ show low correlation coefficients, indicating that the $C_{80}$ is not sensitively influenced by the energy decay curve below $-5 \mathrm{~dB}$.

Moreover, coupling coefficients were calculated to point out the acoustic coupling between the flytower and the stalls area and related to the source position.

The availability of such great number of data will hopefully give rise to further work concerning the spatial distribution of the criteria in the investigated hall, the study of the energy distribution inside the stalls area and a detailed statistical analysis of the criteria.

\section{Acknowledgements}

This research project was supported by CIRI Edilizia e Costruzioni (POS-FESR 2007-2013). The authors gratefully acknowledge the directors and staff of the theatres, who always shared their knowledge and passion, and the MSc thesis students who contributed to the measurement sessions. The authors also wish to thank Prof. Nicola Prodi for sharing his experience and knowledge about Italian historical theatres.

\section{References}

[1] Beranek LL. Concert halls and opera houses: Music, Acoustics and Architecture, Springer, New York 1996.

[2] Bradley JS. A comparison of three classical concert halls. J. Acoust. Soc. Am. 89 (6), 1176-1192, 1991.
[3] Schroeder MR, Gottlob D and Siebrasse KF. Comparative study of European concert halls: correlation of subjective preference with geometric and acoustic parameters. J. Acoust. Soc. Am. 56, 1195-1201, 1974.

[4] Pätynen J, Tervo S and Lokki T. Analysis of concert hall acoustics via visualizations of time-frequency and spatiotemporal responses. J. Acoust. Soc. Am. 133 (2), 842-857, 2013.

[5] Barron M and Lee LJ. Energy relations in concert auditoriums. J. Acoust. Soc. Am. 84 (2), 618-628, 1988.

[6] Gade AC. Acoustical survey of eleven European concert halls A basis for discussion of halls in Denmark. Technical Report 44, The Acoustics Laboratory, Technical University of Denmark, 1989.

[7] Cerdá S, Giménez A and Cibrián R. An Objective Scheme for Ranking Halls and Obtaining Criteria for Improvements and Design. J. Audio Eng. Soc. 60, 419-430, 2012.

[8] Beranek LL. Subjective rank-orderings and acoustical measurements for fifty-eight concert halls. Acta Acustica United with Acustica 89, 494-508, 2003.

[9] Hidaka T and Beranek LL. Objective and subjective evaluations of twenty-three opera houses in Europe, Japan, and the Americas. J. Acoust. Soc. Am. 107 (1), 368-383, 2000.

[10] Hidaka T and Nishihara N. Objective evaluation of chambermusic halls in Europe and Japan. J. Acoust. Soc. Am. 35 (2), 357-372, 2004.

[11] Prodi N. Acoustics of Historical Opera Houses in Italy: past, present and future. Keynote lecture at AIA-DAGA, Meran, 2013.

[12] Cammarata G, Fichera A, Pagano A and Rizzo G. Acoustical prediction in some Italian theatres. Acoustics Research Letters Online 2, 61, 2001.

[13] Martellotta F. The acoustics of Apulian historical theatres: a further development in the research field, in [14] (in italian).

[14] AA.VV., Proc. of Opera houses of the Unification of Italy, Venice, 2011 (in italian).

[15] Pompoli R and Prodi N. Guidelines for acoustical measurements inside historical opera houses: procedures and validation. J. Sound Vib. 232, 281-301, 2000.

[16] Iannace G, Ianniello C, Maffei L, Romano R. Objective measurement of the listening condition in the old Italian opera house "Teatro di San Carlo". J. Sound Vib. 232 (1), 239-249, 2000.

[17] Cocchi A, Garai M and Tavernelli C. Boxes and sound quality in an Italian opera house. J. Sound Vib. 232 (1), 171-191, 2000.

[18] Farina A. Acoustic quality of theatres: correlations between experimental measures and subjective evaluations. Appl. Acoust. 62, 899-916, 2001.

[19] Sakai H, Ando Y, Prodi N and Pompoli R. Temporal and spatial acoustical factors for listeners in the boxes of historical opera theatres. J. Sound Vib. 258 (3), 527-547, 2002.

[20] ISO 3382-1, Acoustics - Measurement of room acoustic parameters. Part 1: Performance spaces, Geneva, 2009.

[21] Fabbri P, Farina A, Fausti P and Pompoli R. The second life of the Teatro degli Intrepidi by Giovan Battista Aleotti through the new techniques of virtual acoustics. Proc. of CIARM95, 2nd Intern. Conf. on Acoustics and Musical Research, Ferrara, May 1995 (in italian).

[22] Prodi N and Pompoli R. The acoustics of three Italian historical theatres: the early days of modern performance spaces. Proc. of Tecniacustica2000, Madrid, October 2000.

[23] Carini Motta F. Treaty about the structure of the theatres and of the scenes. Guastalla, 1676. Republished: Milano, Il Polifilo, 1972 (in italian)

[24] Milizia F. About the theatre. Venezia, Giambattista Pasquali, 1773 (in italian).

[25] Riccati F. About the construction of theatres according to the 
Italian style, i.e. with small boxes. Bassano, Remondini from Venice, 1790 (in italian).

[26] Rizzetti L. "Response to the allegations made to the theatre he proposed", in Collection of scientific and literary brochures from Ferrara. Stamperia Coleti, 1792 (in italian).

[27] Niccolini A. Some ideas on the resonance of the theatre. Napoli, Masi, 1816 (in italian).

[28] Beccega T. On the application of the Greek-Roman architecture to the construction of the modern Italian theatre and to the theatrical machines. Alvisopoli, 1817 (in italian).

[29] Dietrich E, Guski M, Pollow M, Masiero B, Müller-Trapet M, Scharrer R and Vorlænder M. ITA-Toolbox - An Open Source MATLAB Toolbox for Acousticians. Proc. of DAGA, 151-152, Darmstadt, March 2012.

[30] Hak CCJM, Wenmaekers RHC, Hak JPM, Van Luxemburg LCJ, Gade AC. Sound strength calibration methods. Proc. of ICA, Sydney, 2010.

[31] Beranek LL. Analysis of Sabine and Eyring equations and their application to concert hall audience and chair absorption. J. Acoust. Soc. Am. 120 (3) 1399-1410, 2006

[32] Stanzial D, Bonsi D and Prodi N. Measurement of new energetic parameters for the objective characterisation of an opera house. J. Sound Vib. 232 (1), 193-211, 2000

[33] Barron M. "Using the standard on objective measures for concert auditoria, ISO 3382, to give reliable results", Acoust. Sci. $\mathcal{E}$ Tech., 26 (2), 162-169, 2005.

[34] D'Orazio D, De Cesaris S and Garai M. A comparison of methods to compute the "effective duration" of the autocorrelation function and an alternative proposal. J. Acoust. Soc. Am. 130 (4), 1954-1961, 2011.

[35] De Cesaris S, Morandi F, Loreti L, D’Orazio D, Garai M. Notes about the early to late transition in Italian theatres. Proc. of ICSV22, Florence, June 2015.

[36] Galiana M, Llinares C, Page A. Subjective evaluation of music hall acoustics: Response of expert and non-expert users. Build. Environ. 58, 1-13, 2012.

[37] Giménez A, Cibrián RM, Cerdá S, Girón S, Zamarreño T. Mismatches between objective parameters and measured perception assessment in room acoustics: A holistic approach. Build. Environ. 74, 119-131, 2014.

[38] Silingardi V, D’Orazio D, De Cesaris S, Garai M. Musician's subjective perception and objective acoustic descriptors in the stages of historical theatres of Romagna. Proc. of AIA-DAGA, Meran, 2013.

[39] Barron M. Interpretation of Early Decay Times in Concert Auditoria. Acustica 81, 320-331, 1995.

[40] Bradley DT, Wang LM. The effects of simple coupled volume geometry on the objective and subjective results from nonexponential decay. J. Acoust. Soc. Am. 118 (3), 1480-1490, 2005.

[41] Xiang N, Goggans PM. Evaluation of decay times in coupled spaces: Bayesian parameter estimation. J. Acoust. Soc. Am. 110 (3), 1415-1424, 2001.

[42] Xiang N, Goggans PM. Evaluation of decay times in coupled spaces: Bayesian decay model selection. J. Acoust. Soc. Am. 113 (5), 2685-2697, 2003.

[43] Bradley DT, Wang LM. Optimum absorption and aperture parameters for realistic coupled volume spaces determined from computational analysis and subjective testing results. J. Acoust. Soc. Am. 127 (1), 223-232, 2010.

[44] ISO 3382-2, Acoustics - Measurement of room acoustic parameters. Part 2: Reverberation times on ordinary rooms, Geneva, 2008.

[45] Cerdá S, Giménez A, Romero J, Cibrián R and Miralles JL. Room acoustical parameters: a factor analysis approach. Appl. Acoust. 70, 97-109, 2009.
[46] Garai M, De Cesaris S, D'Orazio D. Spatial distribution of monaural acoustical descriptors in historical Italian theaters. Proc. of ISRA 2013, Toronto, Canada 2013. 
Appendix A 
Table 3: Stalls: ISO 3382 [20] criteria averaged in the closed boxes in the eleven Italian historical opera houses analysed in this study. The source positions proscenium and centre stage refer to points SS1 and SS2 in Fig. 3 respectively and the subscript " 3 " indicates the average over the octave bands centred at 500, 1,000 and 2,000 Hz.

\begin{tabular}{|c|c|c|c|c|c|c|c|c|c|}
\hline Theatre & Source & $\begin{array}{c}E D T_{3} \\
(s)\end{array}$ & $\begin{array}{c}T_{30,3} \\
(s)\end{array}$ & $\begin{array}{c}\text { BR } \\
-\end{array}$ & $\begin{array}{l}C_{80,3} \\
(d B)\end{array}$ & $\begin{array}{l}T s_{3} \\
(m s)\end{array}$ & $\begin{array}{c}G_{3} \\
(d B)\end{array}$ & $\begin{array}{c}I A C C_{E 3} \\
-\end{array}$ & $\begin{array}{c}I A C C_{L 3} \\
-\end{array}$ \\
\hline \multirow[t]{2}{*}{ BON } & Proscenium & 1.09 & 1.39 & 1.44 & 4.3 & 65 & 9.0 & 0.43 & 0.23 \\
\hline & Centre stage & 1.33 & 1.70 & 1.27 & 2.6 & 79 & 5.7 & 0.45 & 0.19 \\
\hline \multirow[t]{2}{*}{ ALI } & Proscenium & 0.95 & 1.12 & 1.57 & 5.8 & 52 & 7.2 & 0.45 & 0.21 \\
\hline & Centre stage & 1.11 & 1.21 & 1.50 & 4.0 & 64 & 3.0 & 0.49 & 0.21 \\
\hline \multirow[t]{2}{*}{ MAS } & Proscenium & 1.04 & 1.11 & 1.49 & 4.9 & 60 & 9.2 & 0.43 & 0.18 \\
\hline & Centre stage & 1.21 & 1.13 & 1.47 & 2.8 & 74 & 4.8 & 0.38 & 0.18 \\
\hline \multirow[t]{2}{*}{ ROS } & Proscenium & 0.86 & 1.00 & 1.40 & 6.0 & 49 & 12.4 & 0.41 & 0.22 \\
\hline & Centre stage & 1.04 & 1.02 & 1.42 & 3.7 & 63 & 6.5 & 0.47 & 0.22 \\
\hline \multirow[t]{2}{*}{ STI } & Proscenium & 0.96 & 0.96 & 1.60 & 5.8 & 48 & 10.2 & 0.50 & 0.21 \\
\hline & Centre stage & 1.10 & 1.01 & 1.51 & 2.6 & 71 & 5.8 & 0.48 & 0.21 \\
\hline \multirow[t]{2}{*}{ GOL } & Proscenium & 1.27 & 1.47 & 1.46 & 3.4 & 76 & 12.8 & 0.32 & 0.17 \\
\hline & Centre stage & 1.46 & 1.51 & 1.43 & 2.1 & 89 & 9.1 & 0.34 & 0.17 \\
\hline \multirow[t]{2}{*}{ DRA } & Proscenium & 0.76 & 0.83 & 1.56 & 6.6 & 44 & 10.2 & 0.37 & 0.22 \\
\hline & Centre stage & 0.84 & 0.83 & 1.51 & 5.7 & 49 & 8.1 & 0.41 & 0.22 \\
\hline \multirow[t]{2}{*}{ RUS } & Proscenium & 0.68 & 0.97 & 1.22 & 7.7 & 40 & 11.6 & 0.43 & 0.24 \\
\hline & Centre stage & 0.78 & 1.04 & 1.25 & 6.0 & 49 & 8.7 & 0.43 & 0.23 \\
\hline \multirow[t]{2}{*}{ CES } & Proscenium & 0.85 & 0.90 & 1.56 & 4.6 & 56 & 11.4 & 0.36 & 0.24 \\
\hline & Centre stage & 0.83 & 0.89 & 1.55 & 5.2 & 55 & 9.3 & 0.34 & 0.22 \\
\hline \multirow[t]{2}{*}{ CER } & Proscenium & 0.65 & 0.84 & 1.64 & 7.3 & 42 & 16.2 & 0.39 & 0.26 \\
\hline & Centre stage & 0.68 & 0.78 & 1.74 & 6.9 & 45 & 13.1 & 0.39 & 0.24 \\
\hline \multirow[t]{2}{*}{ PET } & Proscenium & 0.81 & 1.07 & 1.24 & 6.0 & 50 & 15.7 & 0.35 & 0.24 \\
\hline & Centre stage & 0.91 & 1.13 & 1.25 & 4.8 & 59 & 11.8 & 0.37 & 0.22 \\
\hline
\end{tabular}

Table 4: Boxes: ISO 3382 [20] criteria averaged in the closed boxes in the eleven Italian historical opera houses analysed in this study. The source positions proscenium and centre stage refer to points SS1 and SS2 in Fig. 3 respectively and the subscript " 3 " indicates the average over the octave bands centred at 500, 1,000 and 2,000 Hz.

\begin{tabular}{|c|c|c|c|c|c|c|c|c|c|}
\hline Theatre & Source & $\begin{array}{c}E D T_{3} \\
(s)\end{array}$ & $\begin{array}{c}T_{30,3} \\
(s)\end{array}$ & $\begin{array}{c}\text { BR } \\
-\end{array}$ & $\begin{array}{l}C_{80,3} \\
(d B)\end{array}$ & $\begin{array}{l}T s_{3} \\
(m s)\end{array}$ & $\begin{array}{c}G_{3} \\
(d B)\end{array}$ & $\begin{array}{c}I A C C_{E 3} \\
-\end{array}$ & $\begin{array}{c}I A C C_{L 3} \\
-\end{array}$ \\
\hline \multirow[t]{2}{*}{ BON } & Proscenium & 0.98 & 1.38 & 1.41 & 4.2 & 68 & 5.9 & 0.38 & 0.22 \\
\hline & Centre stage & 1.04 & 1.66 & 1.26 & 4.5 & 67 & 4.5 & 0.42 & 0.21 \\
\hline \multirow[t]{2}{*}{ ALI } & Proscenium & 0.88 & 1.14 & 1.49 & 5.1 & 61 & 4.5 & 0.48 & 0.27 \\
\hline & Centre stage & 0.88 & 1.19 & 1.46 & 5.6 & 55 & 2.6 & 0.45 & 0.26 \\
\hline \multirow[t]{2}{*}{ MAS } & Proscenium & 1.04 & 1.13 & 1.47 & 3.3 & 74 & 7.4 & 0.30 & 0.19 \\
\hline & Centre stage & 1.06 & 1.14 & 1.47 & 3.4 & 72 & 5.5 & 0.32 & 0.19 \\
\hline \multirow[t]{2}{*}{ ROS } & Proscenium & 0.79 & 1.00 & 1.40 & 5.6 & 55 & 6.7 & 0.31 & 0.23 \\
\hline & Centre stage & 0.77 & 1.00 & 1.42 & 6.1 & 51 & 5.0 & 0.32 & 0.22 \\
\hline \multirow[t]{2}{*}{ STI } & Proscenium & 0.80 & 0.96 & 1.67 & 5.1 & 59 & 8.2 & 0.31 & 0.21 \\
\hline & Centre stage & 0.86 & 1.01 & 1.56 & 5.0 & 60 & 6.0 & 0.31 & 0.21 \\
\hline \multirow[t]{2}{*}{ GOL } & Proscenium & 1.22 & 1.44 & 1.46 & 2.5 & 85 & 10.4 & 0.34 & 0.19 \\
\hline & Centre stage & 1.25 & 1.47 & 1.43 & 2.9 & 82 & 8.5 & 0.35 & 0.20 \\
\hline \multirow[t]{2}{*}{ DRA } & Proscenium & 0.68 & 0.79 & 1.53 & 6.9 & 46 & 7.4 & 0.36 & 0.26 \\
\hline & Centre stage & 0.68 & 0.79 & 1.54 & 7.0 & 46 & 6.2 & 0.35 & 0.24 \\
\hline \multirow[t]{2}{*}{ RUS } & Proscenium & 0.72 & 1.06 & 1.20 & 6.2 & 51 & 8.6 & 0.35 & 0.22 \\
\hline & Centre stage & 0.75 & 1.07 & 1.22 & 6.1 & 50 & 7.4 & 0.33 & 0.22 \\
\hline \multirow[t]{2}{*}{ CES } & Proscenium & 0.83 & 0.90 & 1.56 & 4.4 & 62 & 9.7 & 0.29 & 0.21 \\
\hline & Centre stage & 0.81 & 0.90 & 1.59 & 4.7 & 61 & 8.4 & 0.29 & 0.23 \\
\hline \multirow[t]{2}{*}{ CER } & Proscenium & 0.67 & 0.78 & 1.70 & 7.1 & 43 & 12.0 & 0.38 & 0.24 \\
\hline & Centre stage & 0.64 & 0.75 & 1.75 & 7.6 & 42 & 10.9 & 0.35 & 0.24 \\
\hline \multirow[t]{2}{*}{ PET } & Proscenium & 0.85 & 1.19 & 1.19 & 4.7 & 61 & 10.4 & 0.30 & 0.21 \\
\hline & Centre stage & 0.83 & 1.20 & 1.16 & 5.1 & 58 & 9.0 & 0.30 & 0.21 \\
\hline
\end{tabular}


Table 5: Gallery: ISO 3382 [20] criteria averaged in the gallery in the eleven Italian historical opera houses analysed in this study. The source positions proscenium and centre stage refer to points SS1 and SS2 in Fig. 3 respectively and the subscript " 3 " indicates the average over the octave bands centred at 500,1,000 and 2,000 Hz.

\begin{tabular}{|c|c|c|c|c|c|c|c|c|c|}
\hline Theatre & Source & $\begin{array}{c}E D T_{3} \\
(s)\end{array}$ & $\begin{array}{c}T_{30,3} \\
(s)\end{array}$ & $\begin{array}{c}\text { BR } \\
-\end{array}$ & $\begin{array}{l}C_{80,3} \\
(d B)\end{array}$ & $\begin{array}{l}T s_{3} \\
(m s)\end{array}$ & $\begin{array}{c}G_{3} \\
(d B)\end{array}$ & $\begin{array}{c}I A C C_{E 3} \\
-\end{array}$ & $\begin{array}{c}I A C C_{L 3} \\
-\end{array}$ \\
\hline \multirow[t]{2}{*}{$\mathrm{BON}$} & Proscenium & 1.15 & 1.40 & 1.41 & 3.1 & 75 & 15.8 & 0.37 & 0.19 \\
\hline & Centre stage & 1.22 & 1.64 & 1.28 & 3.2 & 76 & 13.9 & 0.66 & 0.26 \\
\hline \multirow[t]{2}{*}{ ALI } & Proscenium & 1.44 & 1.55 & 1.31 & -0.5 & 116 & 4.1 & 0.37 & 0.20 \\
\hline & Centre stage & 1.36 & 1.57 & 1.28 & 0.1 & 108 & 3.0 & 0.44 & 0.17 \\
\hline \multirow[t]{2}{*}{ MAS } & Proscenium & 1.19 & 1.14 & 1.47 & 1.4 & 87 & 7.9 & 0.35 & 0.18 \\
\hline & Centre stage & 1.20 & 1.14 & 1.49 & 1.2 & 86 & 6.1 & 0.34 & 0.20 \\
\hline \multirow[t]{2}{*}{ ROS } & Proscenium & 1.28 & 1.13 & 1.35 & 0.1 & 102 & 7.5 & 0.28 & 0.18 \\
\hline & Centre stage & 1.33 & 1.14 & 1.30 & -0.6 & 108 & 3.9 & 0.26 & 0.18 \\
\hline \multirow[t]{2}{*}{ STI } & Proscenium & 1.00 & 1.00 & 1.60 & 2.6 & 77 & 6.2 & 0.28 & 0.20 \\
\hline & Centre stage & 0.96 & 1.02 & 1.51 & 3.6 & 70 & 5.2 & 0.30 & 0.20 \\
\hline \multirow[t]{2}{*}{ GOL } & Proscenium & 1.63 & 1.49 & 1.54 & -2.3 & 137 & 10.9 & 0.25 & 0.17 \\
\hline & Centre stage & 1.70 & 1.53 & 1.46 & -2.5 & 141 & 8.4 & 0.26 & 0.15 \\
\hline \multirow[t]{2}{*}{ DRA } & Proscenium & 0.96 & 0.88 & 1.45 & 3.2 & 71 & 5.5 & 0.32 & 0.19 \\
\hline & Centre stage & 0.93 & 0.87 & 1.44 & 3.0 & 73 & 4.5 & 0.32 & 0.20 \\
\hline \multirow[t]{2}{*}{ RUS } & Proscenium & 1.09 & 1.33 & 1.15 & 3.3 & 74 & 7.3 & 0.31 & 0.19 \\
\hline & Centre stage & 1.09 & 1.33 & 1.14 & 3.4 & 74 & 6.8 & 0.34 & 0.20 \\
\hline \multirow[t]{2}{*}{ CES } & Proscenium & 0.92 & 0.96 & 1.51 & 4.0 & 65 & 9.4 & 0.35 & 0.21 \\
\hline & Centre stage & 0.90 & 0.94 & 1.54 & 4.3 & 63 & 8.4 & 0.33 & 0.21 \\
\hline \multirow[t]{2}{*}{ CER } & Proscenium & 0.66 & 0.79 & 1.69 & 6.7 & 47 & 12.8 & 0.39 & 0.22 \\
\hline & Centre stage & 0.66 & 0.75 & 1.75 & 6.9 & 45 & 11.9 & 0.37 & 0.23 \\
\hline \multirow[t]{2}{*}{ PET } & Proscenium & 0.94 & 1.39 & 1.06 & 4.8 & 61 & 11.5 & 0.39 & 0.19 \\
\hline & Centre stage & 0.98 & 1.39 & 1.08 & 5.1 & 58 & 10.3 & 0.38 & 0.19 \\
\hline
\end{tabular}


Appendix B 
Table 6: Mean value $\mu$, standard deviation $\sigma$ and skewness $s k$ of a selection of ISO 3382 [20] criteria averaged in the stalls in the octave bands centred at 500, 1,000 and 2,000 Hz with source in position SS1 (proscenium).

Stalls statistics - SS1

\begin{tabular}{|c|c|c|c|c|c|c|c|c|c|c|c|c|c|c|c|c|}
\hline & & \multicolumn{3}{|c|}{$E D T$} & \multicolumn{3}{|c|}{$T_{30}$} & \multicolumn{3}{|c|}{$C_{80}$} & \multicolumn{3}{|c|}{$T_{s}$} & \multicolumn{3}{|c|}{$G$} \\
\hline & & 500 & 1000 & 2000 & 500 & 1000 & 2000 & 500 & 1000 & 2000 & 500 & 1000 & 2000 & 500 & 1000 & 2000 \\
\hline \multirow[t]{3}{*}{$\mathrm{BON}$} & $\mu$ & 1.21 & 1.06 & 0.99 & 1.59 & 1.36 & 1.23 & 3.6 & 4.8 & 4.4 & 73 & 58 & 63 & 10.7 & 9.1 & 7.2 \\
\hline & $\sigma$ & 0.16 & 0.17 & 0.16 & 0.05 & 0.05 & 0.04 & 1.4 & 1.3 & 1.9 & 13 & 11 & 15 & 1.1 & 1.2 & 1.5 \\
\hline & $s k$ & -0.01 & -0.19 & -0.53 & 0.04 & 0.04 & -0.32 & 0.20 & 0.79 & 0.39 & -0.42 & -0.65 & -0.53 & 0.55 & 0.99 & 1.19 \\
\hline \multirow[t]{3}{*}{ ALI } & $\mu$ & 1.08 & 0.91 & 0.86 & 1.29 & 1.07 & 1.00 & 4.5 & 6.7 & 6.2 & 62 & 44 & 50 & 8.3 & 7.7 & 5.7 \\
\hline & $\sigma$ & 0.23 & 0.22 & 0.20 & 0.06 & 0.03 & 0.03 & 1.8 & 1.7 & 2.4 & 14 & 11 & 16 & 1.7 & 1.6 & 2.0 \\
\hline & $s k$ & -0.24 & -0.05 & -0.50 & 0.07 & -0.29 & -0.2 & 0.82 & 0.42 & 0.56 & -0.82 & -0.44 & -0.40 & 1.23 & 0.89 & 1.31 \\
\hline \multirow[t]{3}{*}{ MAS } & $\mu$ & 1.14 & 1.02 & 0.97 & 1.18 & 1.11 & 1.05 & 4.2 & 5.3 & 5.1 & 66 & 56 & 59 & 10.2 & 9.2 & 8.3 \\
\hline & $\sigma$ & 0.17 & 0.17 & 0.18 & 0.04 & 0.03 & 0.02 & 1.4 & 1.9 & 2.4 & 14 & 14 & 18 & 1.3 & 1.7 & 2.2 \\
\hline & $s k$ & -0.06 & -0.62 & -1.04 & 0.02 & -0.29 & -0.14 & 0.41 & 1.06 & 1.38 & -0.48 & -0.83 & -1.03 & 0.92 & 1.43 & 1.71 \\
\hline \multirow[t]{3}{*}{ ROS } & $\mu$ & 0.94 & 0.83 & 0.81 & 1.07 & 0.99 & 0.93 & 5.1 & 6.5 & 6.4 & 55 & 46 & 47 & 13.1 & 12.7 & 11.5 \\
\hline & $\sigma$ & 0.16 & 0.19 & 0.18 & 0.04 & 0.03 & 0.02 & 1.2 & 1.4 & 1.8 & 9 & 9 & 13 & 1.1 & 1.1 & 1.5 \\
\hline & $s k$ & -0.09 & 0.20 & 0.33 & -0.34 & 0.00 & -0.36 & 0.79 & 0.56 & 0.43 & $-0,93$ & $-0,85$ & $-0,71$ & 0,94 & 0,94 & 1,49 \\
\hline \multirow[t]{3}{*}{ STI } & $\mu$ & 1.07 & 0.90 & 0.90 & 1.07 & 0.94 & 0.88 & 4.64 & 6.33 & 6.57 & 56 & 45 & 43 & 11.03 & 10.64 & 8.98 \\
\hline & $\sigma$ & 0.25 & 0.24 & 0.27 & 0.04 & 0.03 & 0.03 & 1.4 & 1.8 & 2.5 & 9 & 11 & 15 & 1.61 & 1.98 & 2.42 \\
\hline & $s k$ & -0.17 & -0.28 & -0.25 & -0.39 & -0.51 & -0.36 & 1.20 & 1.09 & 0.39 & -0.36 & -0.77 & -0.13 & 0.44 & 0.77 & 0.88 \\
\hline \multirow[t]{3}{*}{ GOL } & $\mu$ & 1.44 & 1.24 & 1.12 & 1.70 & 1.43 & 1.29 & 2.8 & 3.8 & 3.7 & 84 & 71 & 71 & 13.9 & 12.5 & 12.0 \\
\hline & $\sigma$ & 0.22 & 0.19 & 0.14 & 0.06 & 0.05 & 0.03 & 1.0 & 1.3 & 1.6 & 9 & 12 & 15 & 0.8 & 1.1 & 1.4 \\
\hline & $s k$ & -0.25 & -0.64 & -0.41 & 0.87 & 0.74 & 0.48 & 1.31 & 0.51 & 0.48 & -0.61 & -0.88 & -0.81 & 0.50 & 1.00 & 1.26 \\
\hline \multirow[t]{3}{*}{ DRA } & $\mu$ & 0.87 & 0.72 & 0.69 & 0.98 & 0.80 & 0.72 & 5.4 & 7.1 & 7.2 & 50 & 40 & 41 & 11.6 & 10.1 & 8.9 \\
\hline & $\sigma$ & 0.13 & 0.14 & 0.12 & 0.06 & 0.04 & 0.02 & 1.4 & 1.3 & 1.7 & 8 & 7 & 11 & 1.3 & 2.5 & 3.0 \\
\hline & $s k$ & -0.93 & 0.19 & -0.37 & 0.68 & 0.52 & -0.13 & 0.93 & 0.40 & 0.81 & 0.05 & -0.70 & -0.80 & -1.69 & -5.81 & -4.46 \\
\hline \multirow[t]{3}{*}{ RUS } & $\mu$ & 0.74 & 0.64 & 0.66 & 1.18 & 0.91 & 0.82 & 6.9 & 809 & 8.1 & 45 & 39 & 38 & 12.7 & 11.8 & 10.2 \\
\hline & $\sigma$ & 0.16 & 0.18 & 0.20 & 0.06 & 0.05 & 0.05 & 1.1 & 1.5 & 1.8 & 6 & 6 & 11 & 1.3 & 1.5 & 2.2 \\
\hline & $s k$ & 0.23 & 0.31 & 0.96 & -1.17 & -0.58 & -0.14 & 0.53 & 0.28 & -0.03 & -1.22 & -0.72 & -0.46 & 0.60 & 0.39 & 0.58 \\
\hline \multirow[t]{3}{*}{ CES } & $\mu$ & 0.94 & 0.81 & 0.81 & 1.01 & 0.86 & 0.84 & 3.7 & 5.1 & 5.0 & 64 & 53 & 52 & 12.4 & 11.6 & 10.2 \\
\hline & $\sigma$ & 0.12 & 0.11 & 0.12 & 0.04 & 0.03 & 0.04 & 1.2 & 1.5 & 1.6 & 6 & 7 & 11 & 0.8 & 0.8 & 1.1 \\
\hline & $s k$ & -0.16 & -0.63 & 0.57 & -0.24 & -0.33 & 0.48 & 0.55 & 0.40 & 0.37 & -0.26 & -0.55 & -0.37 & -0.14 & 0.14 & 0.38 \\
\hline \multirow[t]{3}{*}{ CER } & $\mu$ & 0.73 & 0.61 & 0.62 & 0.84 & 0.80 & 0.87 & 6.2 & 8.0 & 7.8 & 47 & 38 & 40 & 17.3 & 16.6 & 14.7 \\
\hline & $\sigma$ & 0.10 & 0.13 & 0.15 & 0.03 & 0.09 & 0.11 & 1.24 & 1.35 & 1.66 & 6 & 5 & 8 & 1.1 & 1.1 & 1.6 \\
\hline & $s k$ & -0.56 & -0.55 & 0.84 & 0.22 & 2.02 & 0.96 & 0.18 & 1.24 & 0.12 & -0.26 & -1.36 & -0.14 & 0.72 & 0.99 & 0.43 \\
\hline \multirow[t]{3}{*}{ LON } & $\mu$ & 0.90 & 0.75 & 0.78 & 1.15 & 1.05 & 0.99 & 5.3 & 6.3 & 6.3 & 55 & 48 & 46 & 16.4 & 15.9 & 14.8 \\
\hline & $\sigma$ & 0.14 & 0.14 & 0.12 & 0.05 & 0.04 & 0.03 & 1.14 & 1.48 & 1.36 & 7 & 6 & 9 & 0.8 & 1.0 & 1.2 \\
\hline & $s k$ & -0.01 & -0.42 & -1.03 & 0.35 & 0.07 & -0.53 & 0.09 & 0.67 & 0.24 & 0.22 & -0.30 & -0.07 & 0.06 & 0.03 & 0.16 \\
\hline
\end{tabular}


Table 7: Mean value $\mu$, standard deviation $\sigma$ and skewness $s k$ of a selection of ISO 3382 [20] criteria averaged in the stalls in the octave bands centred at 500, 1,000 and 2,000 Hz with source in position SS2 (centre stage).

Stalls statistics - SS2

\begin{tabular}{|c|c|c|c|c|c|c|c|c|c|c|c|c|c|c|c|c|}
\hline & & \multicolumn{3}{|c|}{$E D T$} & \multicolumn{3}{|c|}{$T_{30}$} & \multicolumn{3}{|c|}{$C_{80}$} & \multicolumn{3}{|c|}{$T_{s}$} & \multicolumn{3}{|c|}{$G$} \\
\hline & & 500 & 1000 & 2000 & 500 & 1000 & 2000 & 500 & 1000 & 2000 & 500 & 1000 & 2000 & 500 & 1000 & 2000 \\
\hline \multirow[t]{3}{*}{$\mathrm{BON}$} & $\mu$ & 1.54 & 1.30 & 1.14 & 1.91 & 1.69 & 1.51 & 1.3 & 3.6 & 3.0 & 96 & 68 & 73 & 7.2 & 5.7 & 4.1 \\
\hline & $\sigma$ & 0.23 & 0.25 & 0.28 & 0.06 & 0.05 & 0.04 & 1.8 & 1.7 & 3.2 & 11 & 10 & 20 & 0.9 & 0.9 & 1.3 \\
\hline & $s k$ & -0.61 & -0.88 & -0.76 & 0.17 & 0.01 & -0.27 & 0.83 & 0.41 & 0.13 & -0.49 & 0.66 & 0.35 & 3.54 & 2.87 & 1.50 \\
\hline \multirow[t]{3}{*}{ ALI } & $\mu$ & 1.26 & 1.10 & 0.97 & 1.38 & 1.18 & 1.08 & 2.9 & 4.0 & 5.1 & 75 & 64 & 54 & 4.3 & 2.6 & 2.0 \\
\hline & $\sigma$ & 0.24 & 0.29 & 0.29 & 0.06 & 0.04 & 0.03 & 1.6 & 2.4 & 3.4 & 12 & 13 & 19 & 1.3 & 1.5 & 1.6 \\
\hline & $s k$ & -0.05 & -0.40 & -0.03 & 0.13 & -0.01 & -0.54 & 0.75 & 0.81 & 0.04 & -0.12 & -0.19 & 0.75 & 0.44 & 0.89 & 0.49 \\
\hline \multirow[t]{3}{*}{ MAS } & $\mu$ & 1.33 & 1.17 & 1.15 & 1.21 & 1.12 & 1.06 & 2.0 & 3.3 & 3.1 & 83 & 70 & 70 & 5.9 & 4.7 & 3.8 \\
\hline & $\sigma$ & 0.14 & 0.17 & 0.13 & 0.03 & 0.02 & 0.02 & 1.1 & 1.7 & 1.6 & 10 & 9 & 10 & 1.6 & 3.4 & 3.8 \\
\hline & $s k$ & -0.64 & -2.06 & -0.53 & 0.53 & 0.12 & 0.00 & 0.94 & 2.88 & -0.23 & -0.54 & -2.96 & 0.37 & -4.25 & -7.36 & -7.37 \\
\hline \multirow[t]{3}{*}{ ROS } & $\mu$ & 1.14 & 1.00 & 0.98 & 1.11 & 1.01 & 0.95 & 2.7 & 4.2 & 4.1 & 73 & 59 & 59 & 7.5 & 6.8 & 5.3 \\
\hline & $\sigma$ & 0.14 & 0.17 & 0.18 & 0.05 & 0.03 & 0.02 & 1.3 & 1.8 & 2.5 & 10 & 9 & 16 & 1.0 & 1.0 & 1.3 \\
\hline & $s k$ & -0.21 & -0.92 & -1.20 & 0.30 & -0.34 & -0.48 & 0.99 & 0.96 & 0.05 & -0.66 & -0.96 & 0.28 & 0.45 & 1.39 & 1.14 \\
\hline \multirow[t]{3}{*}{ STI } & $\mu$ & 1.22 & 1.04 & 1.04 & 1.15 & 0.99 & 0.91 & 1.7 & 3.2 & 2.9 & 81 & 66 & 67 & 6.9 & 6.2 & 4.3 \\
\hline & $\sigma$ & 0.13 & 0.13 & 0.15 & 0.05 & 0.03 & 0.03 & 1.1 & 1.3 & 2.3 & 9 & 7 & 16 & 1.5 & 1.2 & 1.4 \\
\hline & $s k$ & -0.42 & -0.57 & -1.27 & 0.08 & -0.34 & -0.29 & 0.67 & 0.21 & 0.13 & -0.39 & -0.64 & 0.03 & 0.26 & -0.04 & 0.42 \\
\hline \multirow[t]{3}{*}{ GOL } & $\mu$ & 1.69 & 1.42 & 1.25 & 1.74 & 1.47 & 1.33 & 1.1 & 2.7 & 2.5 & 104 & 81 & 83 & 10.0 & 8.9 & 8.4 \\
\hline & $\sigma$ & 0.17 & 0.15 & 0.14 & 0.05 & 0.04 & 0.03 & 1.1 & 1.3 & 1.5 & 9 & 11 & 12 & 1.0 & 1.1 & 1.2 \\
\hline & $s k$ & -0.03 & -0.88 & -0.95 & 0.28 & 0.16 & -0.09 & 0.43 & 0.30 & 0.28 & -0.59 & -0.45 & -0.28 & 3.19 & 2.93 & 3.20 \\
\hline \multirow[t]{3}{*}{ DRA } & $\mu$ & 0.96 & 0.81 & 0.76 & 0.97 & 0.80 & 0.72 & 4.3 & 6.0 & 6.8 & 59 & 46 & 42 & 9.2 & 7.9 & 7.3 \\
\hline & $\sigma$ & 0.12 & 0.15 & 0.18 & 0.05 & 0.03 & 0.02 & 1.5 & 1.7 & 1.5 & 8 & 6 & 9 & 0.8 & 0.9 & 1.3 \\
\hline & $s k$ & 0.25 & -0.56 & 0.23 & 0.49 & 0.12 & -0.45 & -0.37 & 0.14 & 0.35 & -0.05 & 0.06 & -0.59 & 0.11 & 0.97 & 0.81 \\
\hline \multirow[t]{3}{*}{ RUS } & $\mu$ & 0.91 & 0.71 & 0.73 & 1.26 & 0.97 & 0.89 & 4.6 & 6.8 & 6.6 & 58 & 44 & 46 & 9.9 & 9.1 & 7.1 \\
\hline & $\sigma$ & 0.17 & 0.18 & 0.22 & 0.06 & 0.06 & 0.05 & 1.6 & 1.8 & 2.0 & 7 & 5 & 11 & 1.3 & 1.4 & 1.6 \\
\hline & $s k$ & -0.08 & -0.59 & 0.41 & -1.38 & -1.28 & -0.41 & 0.87 & 0.81 & 0.68 & -1.52 & -1.29 & -0.07 & 0.44 & 0.74 & 0.88 \\
\hline \multirow[t]{3}{*}{ CES } & $\mu$ & 0.95 & 0.79 & 0.75 & 1.01 & 0.87 & 0.80 & 4.1 & 5.2 & 6.1 & 64 & 55 & 47 & 10.4 & 9.3 & 8.1 \\
\hline & $\sigma$ & 0.12 & 0.10 & 0.10 & 0.04 & 0.02 & 0.02 & 1.3 & 1.1 & 1.2 & 9 & 4 & 8 & 1.3 & 0.9 & 1.0 \\
\hline & $s k$ & 0.20 & -1.06 & -1.07 & -0.72 & -0.47 & -0.58 & 0.09 & 1.06 & 0.64 & 0.08 & -0.46 & -0.26 & 0.59 & 0.57 & 0.87 \\
\hline \multirow[t]{3}{*}{ CER } & $\mu$ & 0.80 & 0.65 & 0.60 & 0.87 & 0.75 & 0.71 & 5.7 & 7.1 & 7.9 & 50 & 44 & 41 & 14.6 & 13.1 & 11.6 \\
\hline & $\sigma$ & 0.11 & 0.15 & 0.16 & 0.03 & 0.05 & 0.05 & 1.11 & 1.64 & 2.09 & 6 & 6 & 10 & 1,0 & 1,0 & 1,3 \\
\hline & $s k$ & -0.54 & -0.30 & -0.12 & 0.06 & 1.49 & 1.35 & 0.36 & 0.15 & 0.31 & -0.22 & 0.41 & 0.63 & 0.76 & 0.32 & 1.60 \\
\hline \multirow[t]{3}{*}{ LON } & $\mu$ & 1.01 & 0.87 & 0.85 & 1.20 & 1.12 & 1.05 & 3.7 & 5.1 & 5.5 & 67 & 56 & 52 & 12.9 & 11.9 & 10.6 \\
\hline & $\sigma$ & 0.13 & 0.14 & 0.14 & 0.05 & 0.05 & 0.04 & 1.12 & 1.63 & 1.58 & 6 & 9 & 11 & 0.9 & 1.1 & 1.2 \\
\hline & $s k$ & 0.39 & -0.43 & -0.52 & -0.70 & -0.48 & -0.39 & -0.07 & 0.38 & -0.32 & -0.19 & -0.29 & 0.74 & -0.21 & 0.44 & 0.19 \\
\hline
\end{tabular}

